\title{
Network-based analysis reveals the potential involvement of proteasome subunit alpha-2 in tetralogy of Fallot
}

\author{
Hassan Karami ${ }^{1}$, Maryam Moosavi ${ }^{2}$, Afshin Derakhshani $^{3}$, Ebrahim Miri-Moghaddam ${ }^{4}$, Marlin Touma ${ }^{5}$,
} Behzad Baradaran $^{3}$, Nazila Alizadeh ${ }^{3}$, Hossein Mashhadi Abdolahi ${ }^{6}$, Khalil Hajiasgharzadeh ${ }^{3 *}$ (D), Hossein Safarpour ${ }^{7 * \text { iD }}$

1. Student Research Committee, Birjand University of Medical Sciences, Birjand, Iran

2. Department of Molecular Medicine, Faculty of Medicine, Birjand University of Medical Sciences, Birjand, Iran

3. Immunology Research Center, Tabriz University of Medical Sciences, Tabriz, Iran

4. Cardiovascular Diseases Research Center, Birjand University of Medical Sciences, Birjand, Iran

5. Department of Pediatrics, David Geffen School of Medicine, University of California, Los Angeles, United States

6. Tabriz Health Services Management Research Centre, Tabriz University of Medical Sciences, Tabriz, Iran

7. Cellular and Molecular Research Center, Birjand University of Medical Sciences, Birjand, Iran

\begin{abstract}
Introduction: Tetralogy of Fallot (TOF) is the most common cyanotic form of congenital heart defects. However, there is no effective therapeutic approach and current therapies have limited curative efficacy. Moreover, the exact etiology of TOF has remained largely unknown. Improved understanding of molecular mechanisms can give an insight into TOF pathogenesis and development of therapeutic approaches.
\end{abstract}

Methods: Here, we conducted a systematic study on the right ventricular myocardium of 24 infants (16 ToF/8 control) using weighted gene co-expression network analysis (WGCNA) to identify meaningful modules or candidate biomarkers.

Results: Co-expression network analysis by WGCNA suggested that a highly preserved turquoise module with 2,493 genes and a $P$-value of $3 \times 10^{-11}$ was significantly correlated to TOF. The top 5 hub genes of this module were PSMA2, MYL12A, C11ORF71, COMMD6, and CREG1. The result of turquoise module enrichment showed that the most correlation topic in biological processes and KEGG pathways were positive regulation of cardiac neural crest migration involved in outflow tract morphogenesis and positive regulation of neural crest cell differentiation. Also, we recognized 4 FDA-approved drug candidates for other indications could potentially use for the treatment of TOF patients through regulation of two hub genes of the coexpression network (PSMA2 and NDUFA4). Our findings also showed that the 13 experimentally validated microRNAs regulated the co-expression network through 5 hub genes.

Conclusion: We systematically recognized co-expressed gene modules and hub genes associated with TOF progression, which offered insights into the mechanisms underlying TOF progression and some potential drugs for the treatment of TOF.

\section{Keywords:}

Congenital Heart Defects; Tetralogy of Fallot; Systems Biology; miRNAs;

Drug Repositioning

\section{* Corresponding authors:}

K. Hajiasgharzadeh

Email:

hajiasgharzadeh@tbzmed.ac.ir

\section{H. Safarpour}

Email:

h.safarpour@bums.ac.ir

Tel: +98 (563) 2381258

Received 18 December 2019; Received in revised form 31 July 2020; Accepted 25 August 2020 


\section{Introduction}

Tetralogy of Fallot (TOF) is the most common cyanotic form of congenital heart defects (CHDs) occurs in 1 out of every 3,000 live births and is a major cause of infant death due to progressive malformations (Michielon et al., 2006). Genetic and environmental risk factors can interrupt the wellcontrolled molecular development process (Cecchetto et al., 2010; Michielon et al., 2006). The TOF heart is characterized by ventricular septal defect, overriding of the aorta, right ventricular outflow stenosis and right ventricular hypertrophy (Apitz et al., 2009). The survival rates of TOF patients after surgical repair appear to be around 85 percent. Although individuals with TOF have a normal lifespan after the repair, approximately 10-15 percent of them suffer from late complications, including ventricular arrhythmia leading to sudden death and right ventricular dysfunction resulting from pulmonary stenosis. A precise understanding of the molecular mechanisms that underlie the progression to ventricular failure is important not only to recover late functional status but also to prevent sudden deaths after surgery (d'Udekem et al., 2000; Meijer et al., 2005; Nollert et al., 1997). Currently, surgical therapy is the most common therapy for TOF, but it has failed to prevent lifetime complications and there is a probability of late reoperation in some patients (Gu et al., 2014). Despite major progress, the precise etiology of TOF like most other CHDs remains unknown. Only $20 \%$ of CHD is associated with chromosomal abnormalities and/or genetic defects. Others have been regarded as multifactorial, in which genetic and environmental factors play a critical role in their pathogenesis (Villafañe et al., 2013; Wang et al., 2014). Common chromosomal alternations in patients with TOF include trisomy 21, 18 and 13 and 22q11.2 microdeletions, as well as other less common abnormalities in some cases (Villafañe et al., 2013). Several microarray studies have revealed that certain microRNAs may be dysregulated in the cardiac tissue of TOF patients (Bittel et al., 2014; Liang et al., 2014; Wang et al., 2018). Furthermore, previous evidence has verified that an evolutionarily preserved complex of transcription factors that link signaling pathways with genes involved in muscle development, remodeling, and contractility, including GATA and NKX families, has a central character in early cardiogenesis (Bartlett et al., 2010; Hu et al.,
2010). Meanwhile, the correlation between TOF and certain gene mutations has been found, but little is known about the roles of these genes in embryonic development, tissue homeostasis, and cardiovascular disease ( $\mathrm{Gu}$ et al., 2014; Nemer et al., 2006). Improved understanding of the main causes of TOF can give an insight into the pathogenesis and make the prediction of the disease risk possible ( $\mathrm{Xu}$ et al., 2014). In addition, the precise recognition of genetic culprits can achieve a better prognosis after surgical repair (Apitz et al., 2009). Recently, the use of correlation networks in bioinformatics applications has been widely attracting. A new method called Weighted Gene Co-expression Network Analysis (WGCNA) has been developed for the construction of relationship networks by grouping functionally high related gene clusters into several modules, which is a powerful tool for identifying key pathways perturbed in disease using gene expression microarray data (Langfelder and Horvath, 2008; Pei et al., 2017). In the present study, we aim to identify the coexpression gene network to examine the molecular mechanisms of TOF by employing WGCNA using microarray gene expression data. The candidate genes identified by the presented approach can give new insights into TOF therapy.

\section{Materials and methods}

\section{Gene expression datasets}

The gene expression profile of TOF was downloaded from the Gene Expression Omnibus (GEO) database with the accession number of GSE35776, which is based on the platform of GPL5175 [HuEx-1_0st] Affymetrix Human Exon 1.0 ST Array. From this dataset, the gene expression data of 16 infants (11 male $/ 5$ female) $<1$ year of age with non-syndromic TOF without a 22q11.2 deletion requiring surgical correction and 8 ( 3 male/5 female) normally heart developing infants were used in the present study. The raw data were modified and normalized using the affy package of R 3.4.1 in Bioconductor (Gautier et al., 2004; Gentleman et al., 2004). The top 4,000 genes with expression coefficient of variance equal to or more than 0.05 were selected.

The other microarray dataset referenced in this study was downloaded from NCBI GEO with accession number GSE26125. This dataset was used to conduct module preservation analysis. GSE26125 contains 21 tissue samples mRNA expression profile 
of infants with TOF $(n=16)$ and control samples $(n=5)$ based on the platform of GPL11329 CodeLink Human Whole Genome Bioarray.

\section{Identification of differentially expressed genes (DEGs)}

GEO2R (https://www.ncbi.nlm.nih.gov/geo/geo2r/), an R-associated web application, was applied to filtrate DEGs among TOF and normal samples. The DEGs which met the following criteria: $P$-value $<$ 0.05 , and $\left|\log _{2} F C\right| \geq 2$, were selected for further analysis.

\section{WGCNA network construction and module identification}

The co-expression network analysis was constructed following the WGCNA protocol (Langfelder and Horvath, 2008; Pei et al., 2017). A Pearson correlation coefficient was computed to detect differentially co-expressed links, and the threshold power $\beta$ was selected to create the adjacency matrix and to adjust the property of scale-free networks. The topological overlap matrix was constructed that appertains to the interconnection between two genes and applies for the clustering of genes with high topological overlap to the same module. Module identification was performed using the dynamic tree cut algorithm with a minimum module size of 30 genes. Modules with high similarity scores were merged due to module eigengene distance threshold of 0.1 .

\section{Module preservation analysis}

The preservation median rank implemented in WGCNA was used to detect the conservation of gene pairs between two networks by determining the mean median ranks of connectivity and density for each module (Langfelder and Horvath, 2008; Pei et al., 2017). $Z_{\text {summary }}$ was used to assess the significance of observed module preservation statistics and defined as the mean of $Z$ scores computed for density and connectivity of sub-networks, in which $Z_{\text {summary }}<2$ shows no preservation, $2<Z_{\text {summary }}<10$ indicates weak-moderate preservation and $Z_{\text {summary }}>10$ suggested strong evidence for preservation.

\section{Feature vectors in WGCNA network}

To identify modules that were significantly associated with the clinical trait (TOF), expression profiles of each module were summarized via its module eigengene (ME) to the first principal component of the expression matrix (Langfelder and Horvath, 2008; Pei et al., 2017). The gene significance (GS) value was used for measuring of individual genes associations with the TOF. Also, module membership (MM) was defined as the correlation of the ME and the gene expression profile for each module. Finally, genes with both $G S$ and $M M \geq 0.8$ were chosen as hubgenes if differentially expressed compared to control samples.

\section{Evaluation of selected hub genes behavior in response to corrective heart surgery}

To evaluate transcriptional changes of selected Hub genes in response to cardiopulmonary bypass (CPB), we performed DEG analysis on GSE132176 which consists of right atrium tissues from 10 children affected by TOF before (Pre-CPB) and after (PostCPB) surgery.

\section{Evaluation of selected hub genes behavior in response to chronic hypoxia}

To further elucidation of gene expression profiles of selected Hub genes in the chronically hypoxic cyanotic myocardium, we used GSE14970 containing 12 samples of the right ventricle of $(n=6)$ or acyanotic $(n=6)$ pediatrics with TOF collected immediately after the institution of CPB. The goal of this analysis was to illustrate hypoxia-dependent induction of transcriptomic changes in TOf myocardium after birth.

\section{Functional annotation and enrichment analysis of modules}

The ClueGO (version 2.2.5) Plug-in tool on Cytoscape (version 3.6.0) was used to identify and visualized the enriched gene ontology (GO), KEGG pathway and biological pathways in interesting modules genes (kappa score $=0.4$ ) (Bindea et al., 2009; Shannon et al., 2003).

\section{Identification of candidate regulatory miRNAs and drugs}

The miRTarBase 7.0 database and CyTargetLinker plugin of Cytoscape was employed to identify experimentally validated miRNAs and FDA approved drugs interact with hub genes of interesting modules. Furthermore, the mRNA-miRNA-drug tripartite network was reconstructed to visualize the network 
A Module-trait relationships
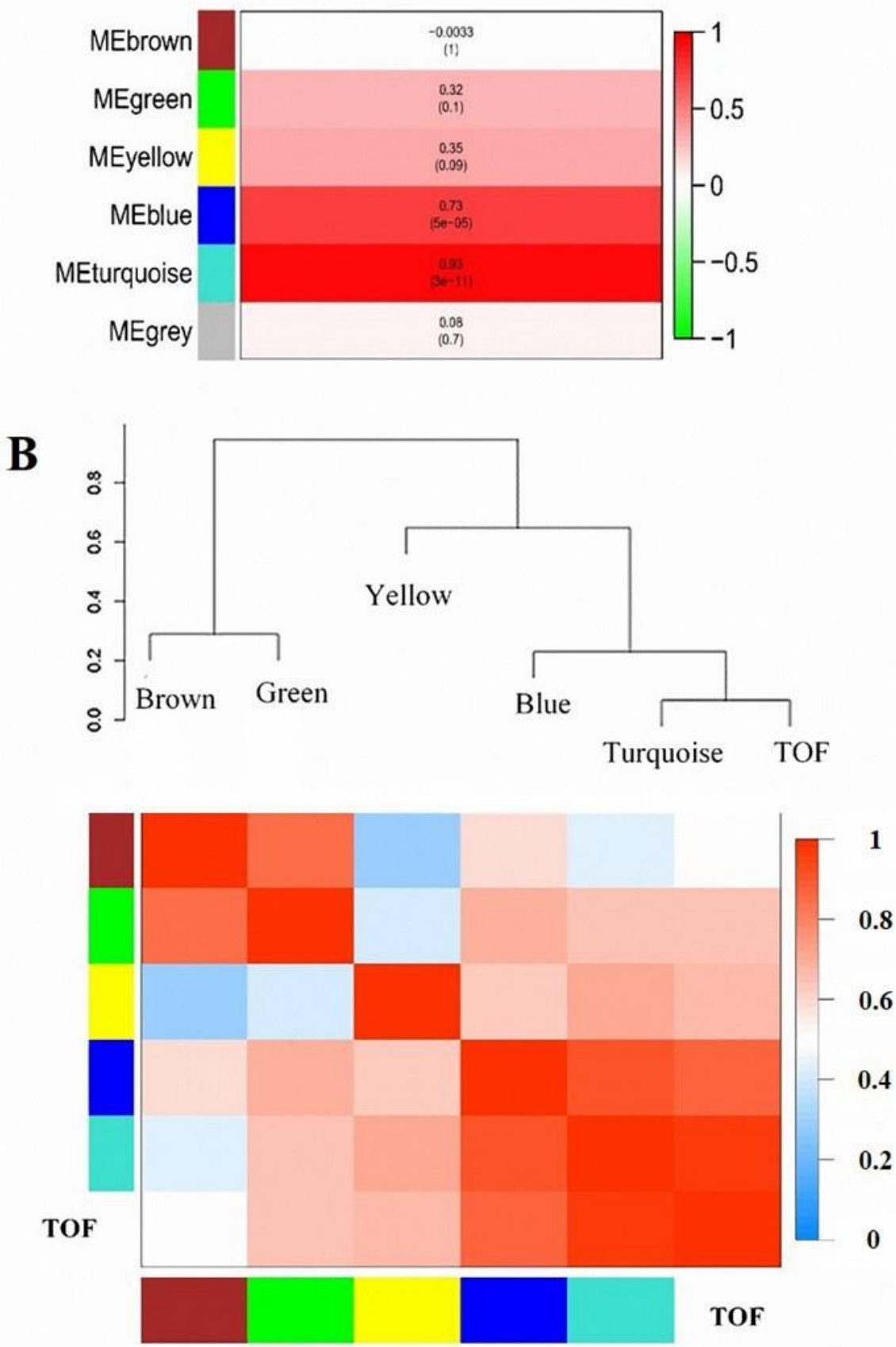

Fig.1. (A) Module-trait relationship. Each row corresponds to a module eigengene and the column corresponds to disease status (TOF vs. Control). Numbers in each cell represent the corresponding correlation and $P$-value; (B) Module-module associations. Eigengene dendrogram and heatmap plot of the adjacencies in the eigengene network including the state which represents the relationships among the modules and the TOF status.

data using Cytoscape software (version 3.6.0).

\section{Results}

\section{Weighted co-expression gene network construction using WGCNA}

The GSE35776 data set was used in this study. We performed quantile normalization to reduce the effects of technical noises. The plot of the quantile of expression levels across arrays is shown in Figure S1. No outliers were observed in 24 samples by hierarchical average linkage clustering, thus all samples were included in the analysis (Fig. S2). A $\beta=8$ was selected as a scale-free topology criterion (Fig. S3) and the WGCNA package was used for reconstruction of the weighted co-expression network for TOF patients and normal groups. The result of the 


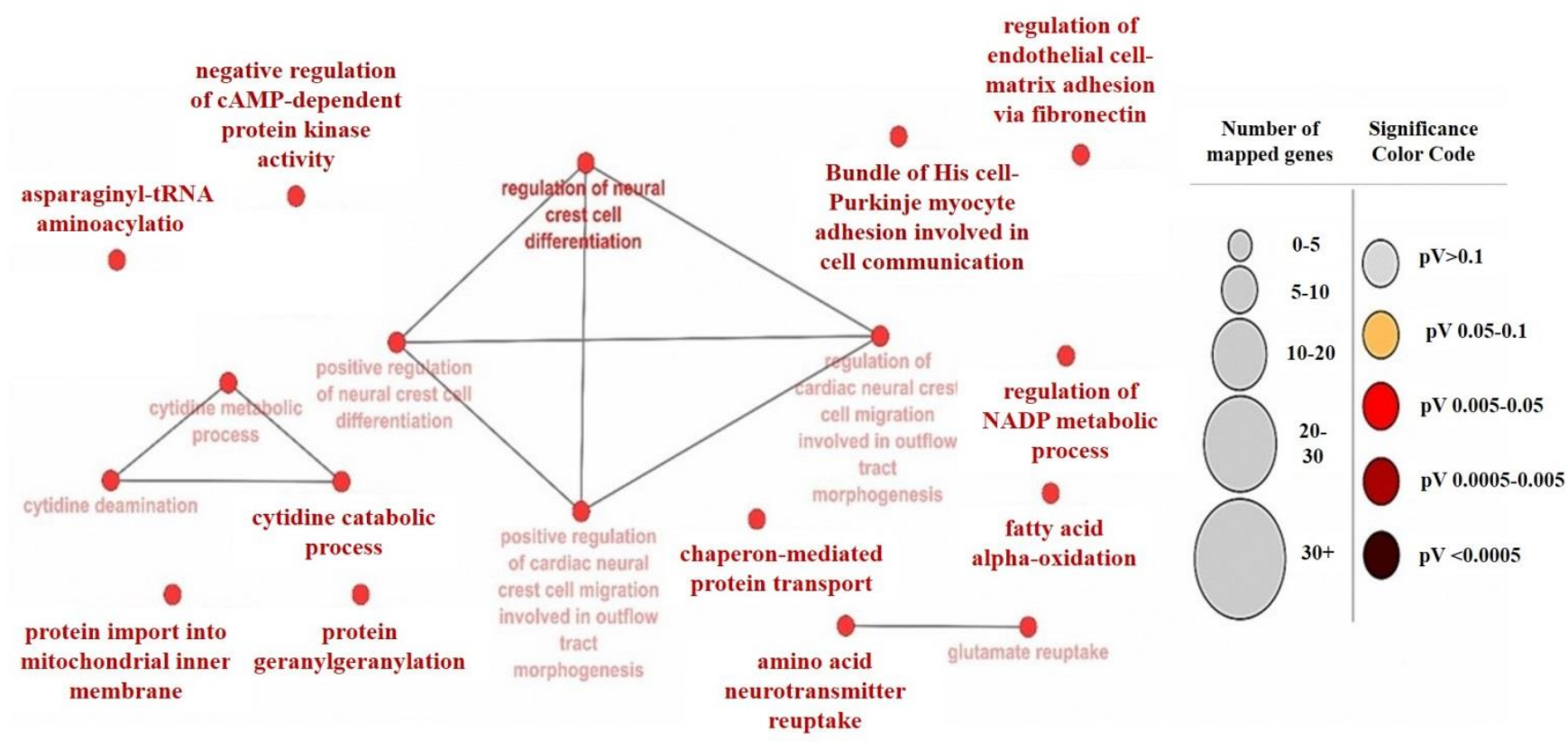

Fig.2. Processes and pathways identified within the turquoise module. Gene ontology and pathway analysis were performed using significant genes across all datasets. Node size corresponds to the number of associated genes, and node color reflects the statistical significance. The darker the pathway node, the more statistically significant it is, with a gradient from red ( $P$-value $0.05-0.005)$ to black $(P<0.0005)$.

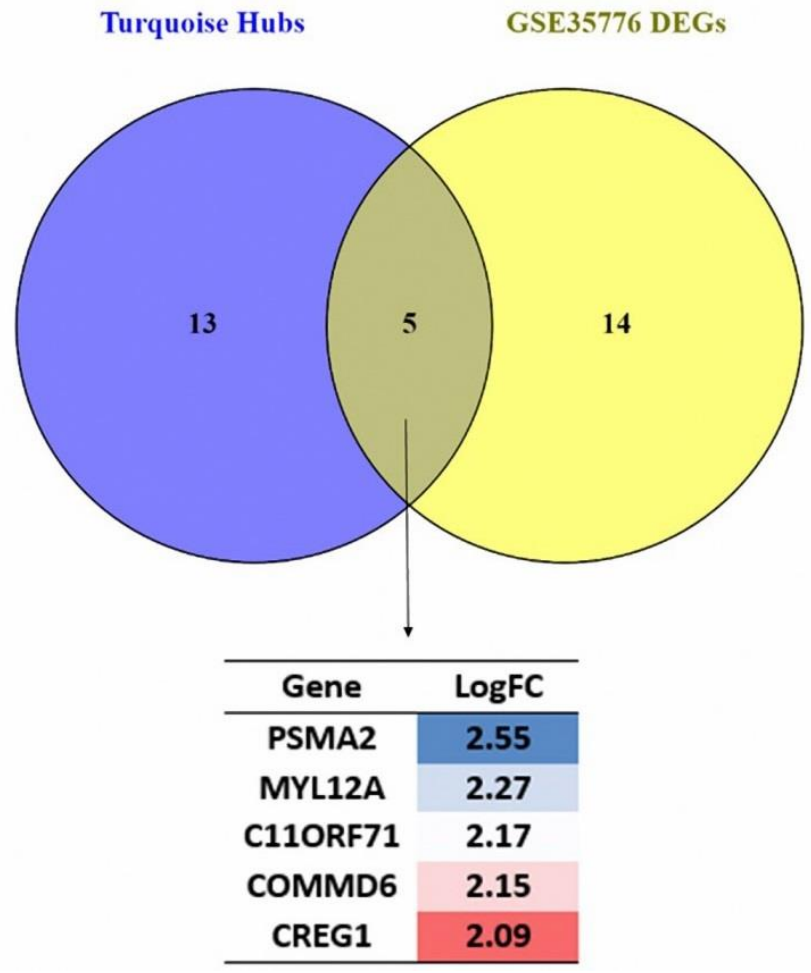

Fig.3. Selection of best hub-genes for the reconstruction of the co-expression network. Hub-genes with GS and MM>0.95 and logarithmic fold changes $(|\operatorname{LogFC}|)>2$ were selected.

dynamic tree cut (Fig. S4) gave 5 co-expressed modules with a range size of 58 (green) to 2,493 (turquoise) genes. A grey module was assigned for 249 genes that failed to classify as a distinct coexpression module and was eliminated from further analysis (Table 1 ).

\section{Identification of DEGs}

A total of 197 genes were primarily identified as DEGs with the GEO2R default thresholds, including 179 up-regulated and 18 down-regulated genes. These 197 DEGs were then screened based on the following criteria: $P$-value $<0.05$, and $\left|\log _{2} \mathrm{FC}\right| \geq 2$. 


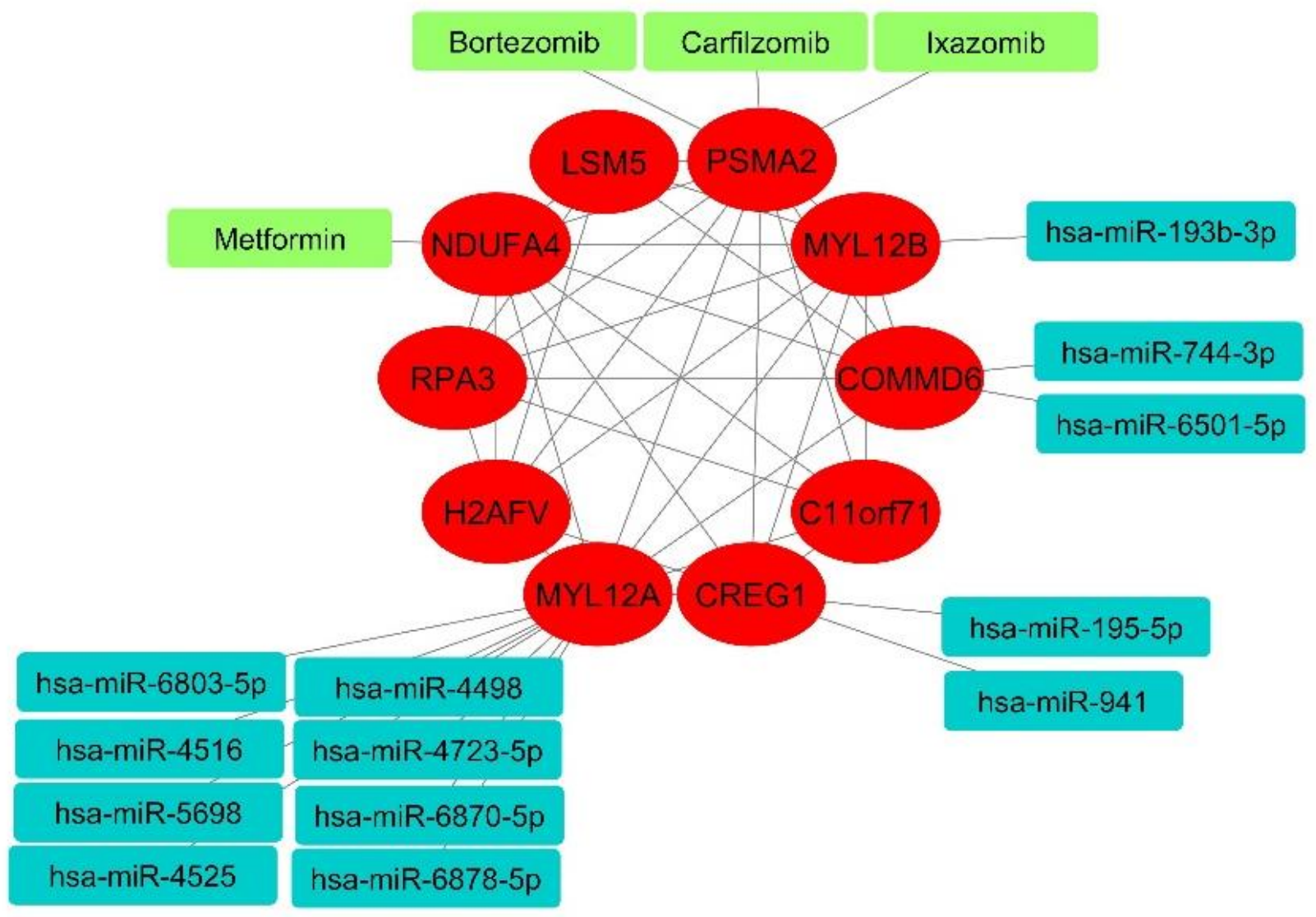

Fig.4. Co-expression network and related microRNA and drugs of the turquoise module.

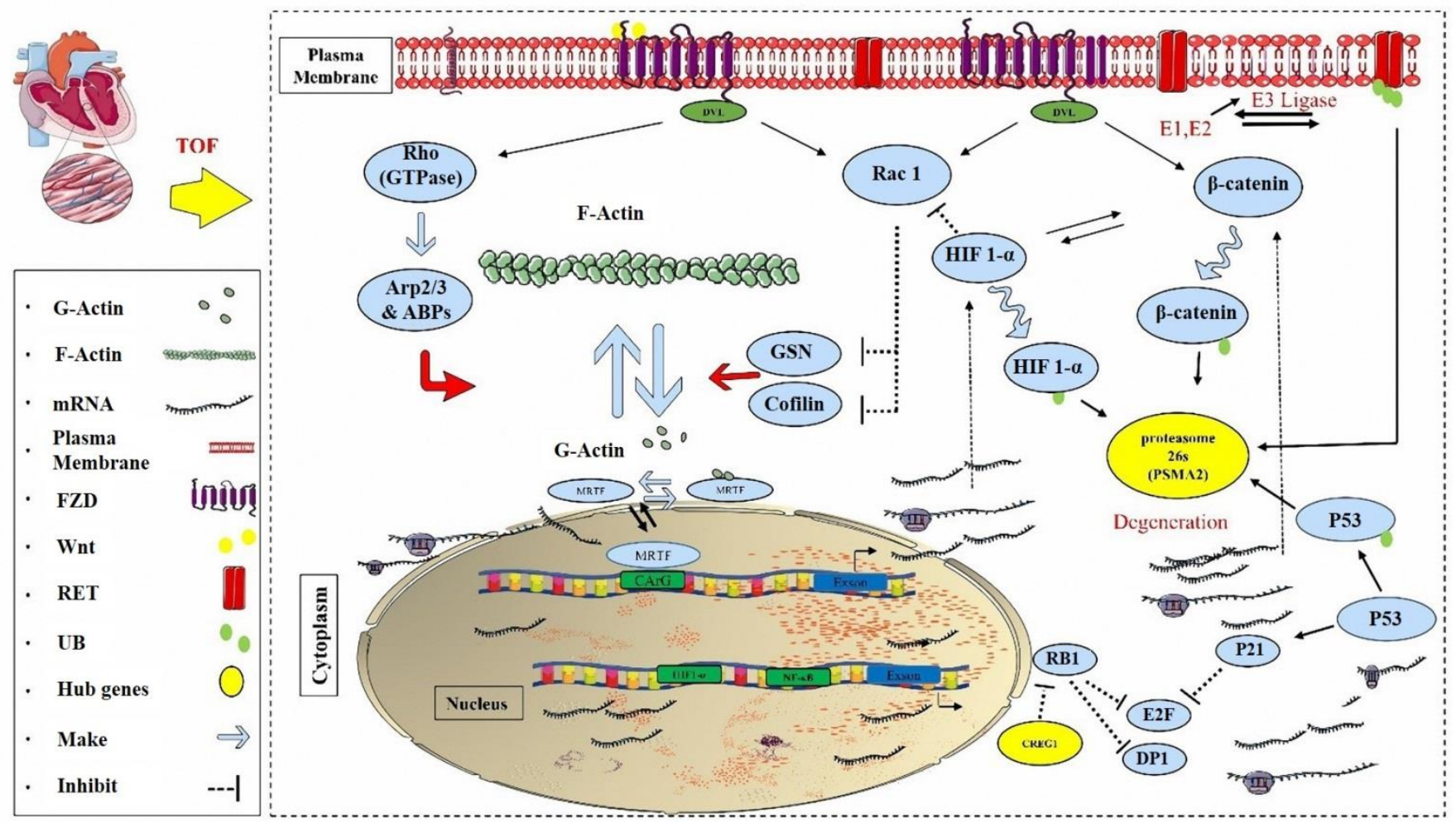

Fig.5. A suggested mechanism for the tetralogy of Fallot pathogenicity. Rho: Rho factor, Rac1: Ras-related C3 botulinum toxin substrate 1; DVL: Dishevelled segment polarity protein; MRTF: Myocardin related transcription factor; RB1: RB transcriptional corepressor 1; CREG1: Cellular repressor of E1A stimulated genes 1; FZD: Frizzled class receptor; RET: Ret proto-oncogene; UB: Ubiquitin. 
Table 1: Module colors characterization. The co-expression modules identified by WGCNA.

\begin{tabular}{lccccc}
\hline & Module Colors & Number of Genes & correlation & $\boldsymbol{p}$-value & Module preservation \\
\hline $\mathbf{1}$ & Blue & 1016 & 0.73 & $5.00 \mathrm{e}-05$ & GSE26125 \\
\hline $\mathbf{2}$ & Brown & 103 & -0.0033 & 1 & 2.90 \\
\hline $\mathbf{3}$ & Green & 58 & 0.32 & 0.1 & 0.75 \\
\hline $\mathbf{4}$ & Grey & 249 & 0.08 & 0.7 & -0.28 \\
\hline $\mathbf{5}$ & Turquoise & 2493 & 0.93 & $3.00 \mathrm{E}-11$ & -0.48 \\
\hline $\mathbf{6}$ & Yellow & 81 & 0.35 & 0.09 & 4.80 \\
\hline
\end{tabular}

Table 2: Effects of cardiac surgery (CPB) and chronic hypoxia on ToF-related Hub genes

\begin{tabular}{cccccc}
\hline $\begin{array}{c}\text { GEO } \\
\text { accession } \\
\text { number }\end{array}$ & GSE35776 & GSE26125 & GSE132176 & $\begin{array}{c}\text { GSE38177\&GS } \\
\text { E14956 }\end{array}$ & $\begin{array}{c}\text { GSE261 } \\
25\end{array}$ \\
\hline Tissue & Right ventricle & Right ventricle & Right atrium & Right ventricle & $\begin{array}{c}\text { Right } \\
\text { ventricle }\end{array}$ \\
\hline Conditions & ToF disorder & ToF disorder & CBP & CPB & $\begin{array}{c}\text { Chronic } \\
\text { hypoxia }\end{array}$ \\
\hline PSMA2 & 2.55 & 3.54 & -0.55 & -0.32 & 0.41 \\
\hline MYL12A & 2.27 & 2.58 & $\mathrm{~ns}$ & $\mathrm{~ns}$ & 0.81 \\
\hline C11ORF71 & 2.17 & 1.88 & $\mathrm{~ns}$ & $\mathrm{~ns}$ & $\mathrm{~ns}$ \\
\hline COMMD6 & 2.15 & 1.65 & 0.29 & -0.11 & 0.43 \\
\hline
\end{tabular}

Next, the resulted 19 DEGs which were met the criteria, selected for subsequent analysis.

\section{Module-trait and module-module association}

Investigating the correlation between module eigengenes and the trait and module-module relationship revealed that the turquoise module ( $r=0.93, P$-value=3.00e-11) was the most positively correlated modules with TOF (Fig. 1).

\section{Preservation of co-expression modules}

To assess the stability and conservation of GSE35776 network modules, network preservation analysis was performed to compare them with the GSE25126 network modules. According to preservation median rank and $Z_{\text {summary }}$ outcomes, a turquoise module with $Z_{\text {summary }}$ of 4.8 was considered as a weak-moderate-preserved module (Fig. S5).

\section{Functional enrichment analysis of interesting module}

The enrichment of meaningful biological processes of the aforementioned modules genes with its interactions was visualized by the ClueGo tool. As shown in Figure 2, positive regulation of cardiac neural crest migration involved in outflow tract morphogenesis and positive regulation of neural crest cell differentiation were enriched in the turquoise module.

\section{Identifying Hub genes and network analysis of} the favorite modules

Hub genes were detected based on network unique properties, including gene significance (GS) and module membership (MM), genes with high GS and MM were significantly correlated with TOF (Fig. S6). Hub genes with GS and MM > 0.95 and logarithmic fold changes (LogFC) $>2.00$ were selected from the final ranked genes and listed in Figure 3 . Reconstruction of the co-expression network of the turquoise module was accomplished using the GeneMANIA database within the Cytoscape network visualization tool (Fig. 4).

\section{Evaluation of selected hub genes behavior in response to corrective heart surgery}

The gene expression patterns of selected hub genes were compared before and after CPB. As indicated in Table 2, proteasome subunit alpha-2 (PSMA2), cellular repressor of $E 1 A$ stimulated genes-1 (CREG1) and COMM domain containing-6 (COMMD6) hub genes present a similar expression 


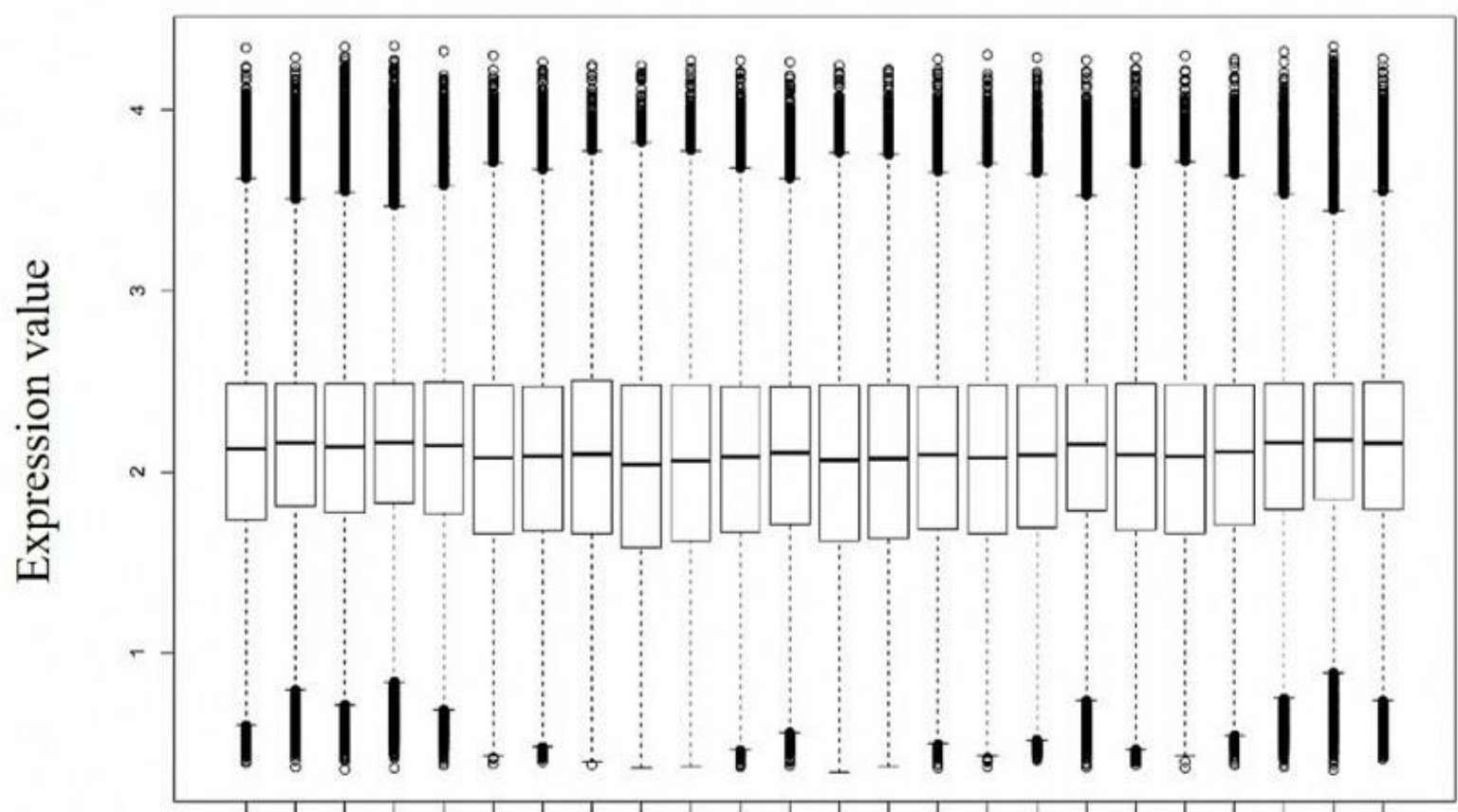

GSM874656 GSM874659 GSM874662 GSM874665 GSM874668 GSM87467] GSM874674 GSM874677

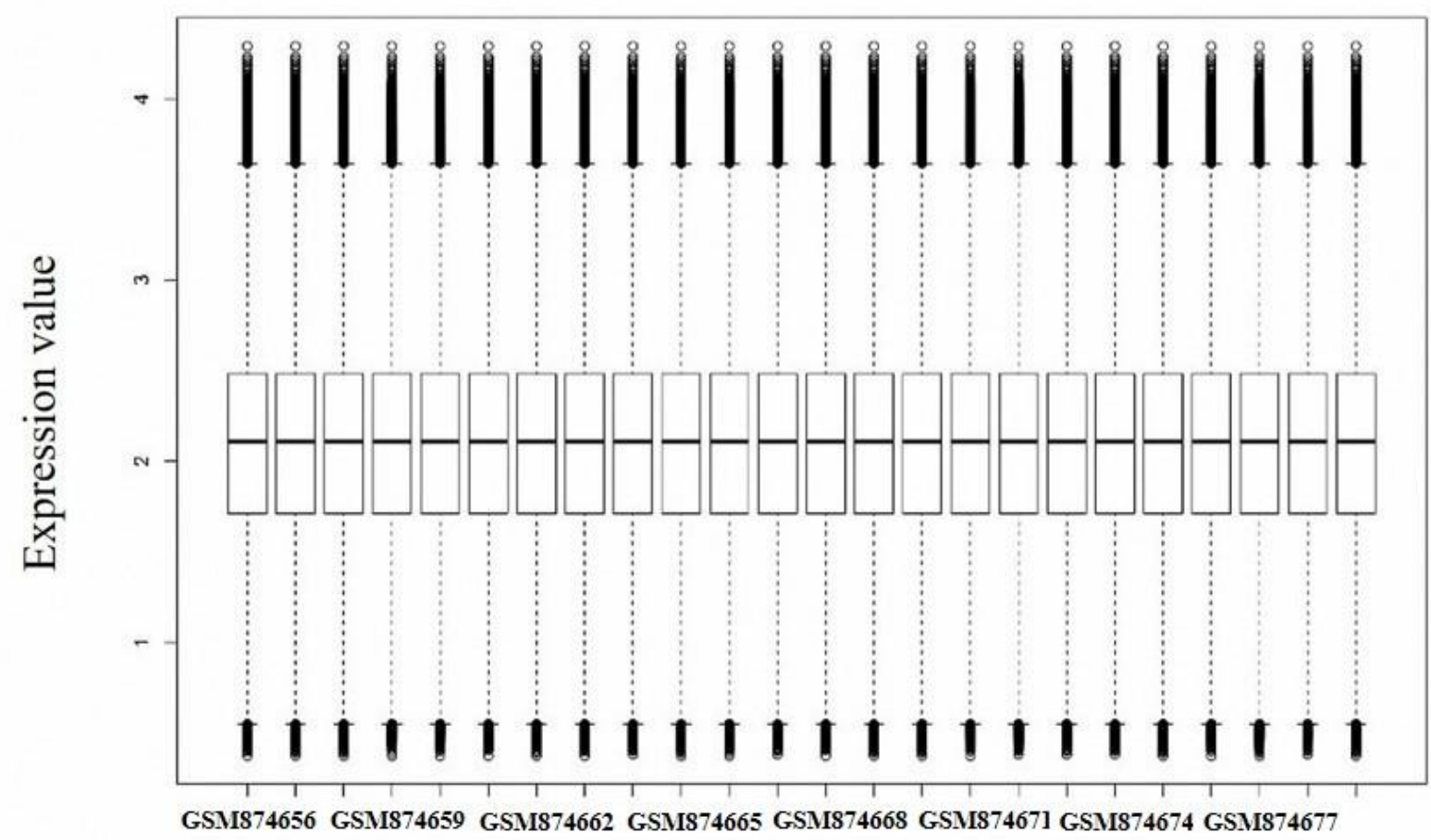

Fig.5. A suggested mechanism for the tetralogy of Fallot pathogenicity. Rho: Rho factor, Rac1: Ras-related C3 botulinum toxin substrate 1; DVL: Dishevelled segment polarity protein; MRTF: Myocardin related transcription factor; RB1: RB transcriptional corepressor 1; CREG1: Cellular repressor of E1A stimulated genes 1; FZD: Frizzled class receptor; RET: Ret proto-oncogene; UB: Ubiquitin. 


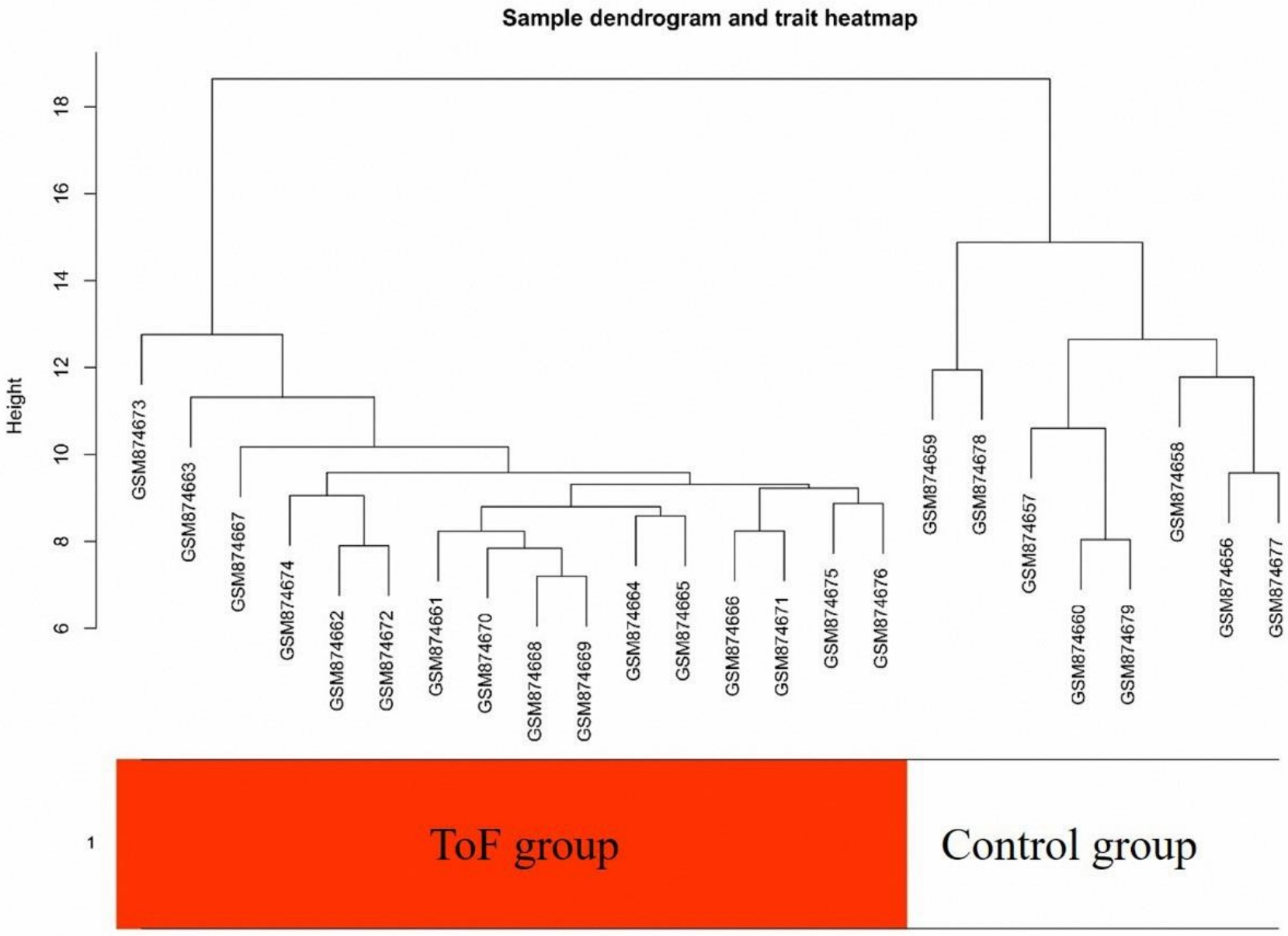

Fig.S2. Sample clustering to detect outliers. The color is proportional to the pathological stage (Red=TOF samples and white=normal samples).

pattern showing decreased expression following CPB. These findings suggest a potential role of PSMA2, CREG1 and COMMD6 as novel biomarkers of myocardial response to surgical stress and diagnostic and prognostic targets of postsurgical therapy.

\section{Evaluation of selected hub genes behavior in response to chronic hypoxia}

The differential expression analysis of selected hub genes detected a reprogramming response to chronic hypoxia due to the upregulation of myosin light chain 12A (MYL12A), COMMD6, PSMA2 and CREG1 indicating that observed transcriptional dysregulation of selected Hub genes in TOF myocardium is attributable, in part, to the existing hypoxic environment in cyanotic TOF hearts after birth (Table 2).

\section{MicroRNAs as upstream regulators for common hub-genes}

In order to find the potential molecular mechanisms of the hub-genes, their predicted microRNAs were analyzed by the miRWalk database. The 13 experimentally validated miRNAs were shown in Figure 4. As a result, the 5 hub genes regulated by these microRNAs were MYL12A, CREG1, H2AF7, COMMD6 and NDUFA4.

\section{Drug-target network construction}

To analyze the drug development perspective of the turquoise module, we tested if it harbors known targets of TOF drugs. We also searched the module for drug targets not currently approved for TOF treatment. These targets in the module included: PSMA2 (carfilzomib, bortezomib and ixazomib) and NDUFA4 (metformin hydrochloride) (Fig. 4). The presence targets in the module of interest suggested that these drugs potentially impact TOF and could be considered as possible candidates for further research in this respect.

\section{Suggested mechanism of TOF pathogenesis}

Based on genes involved in the co-expression 

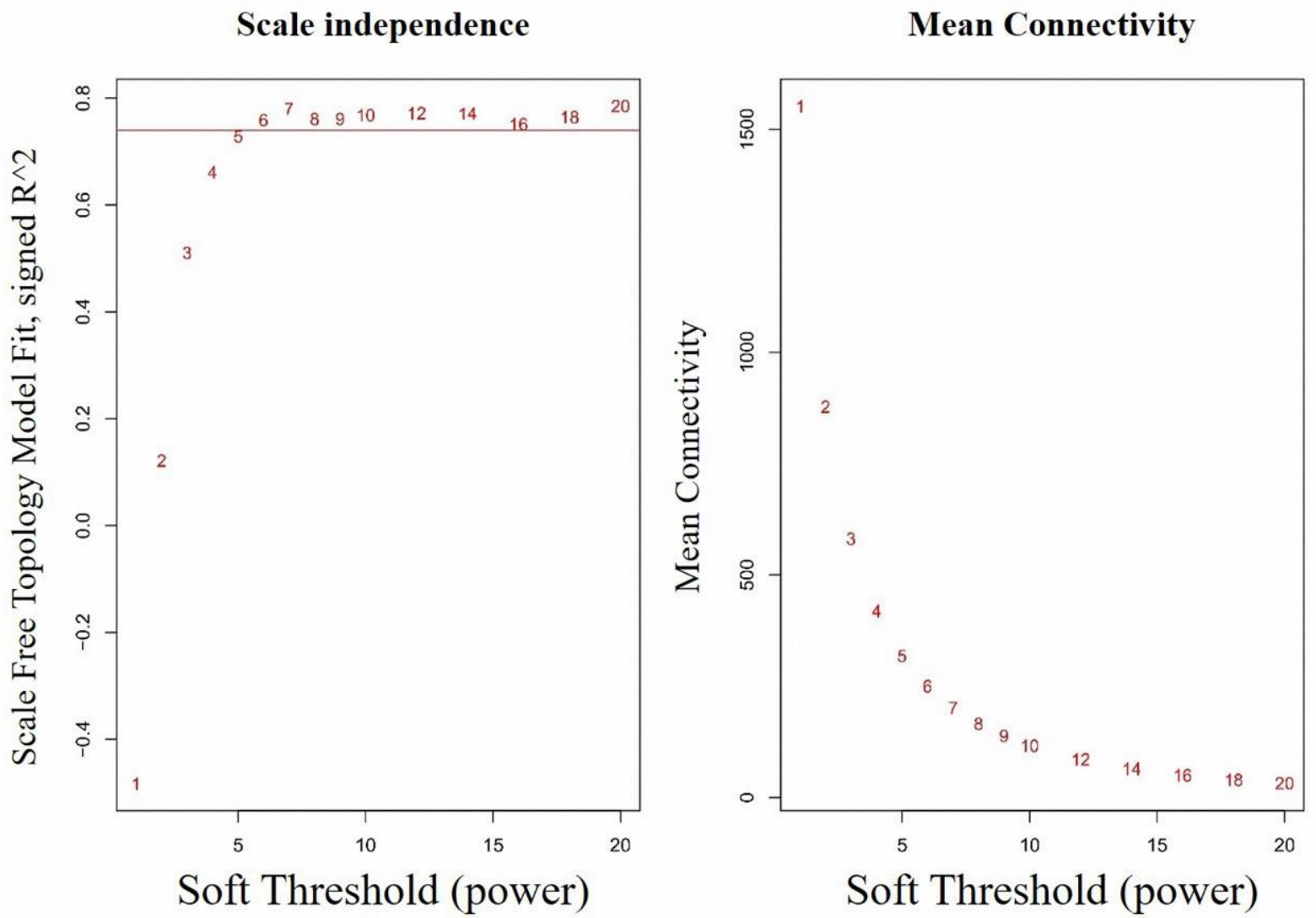

Fig.S3. Selection of the soft-thresholding powers. Selection of the soft-thresholding powers. The left panel shows the scalefree fit index (y-axis) as a function of the soft-thresholding power (x-axis). The right panel displays the mean connectivity (degree, $y$-axis) as a function of the soft-thresholding power ( $x$-axis). The power was set as 10 for the next analysis.

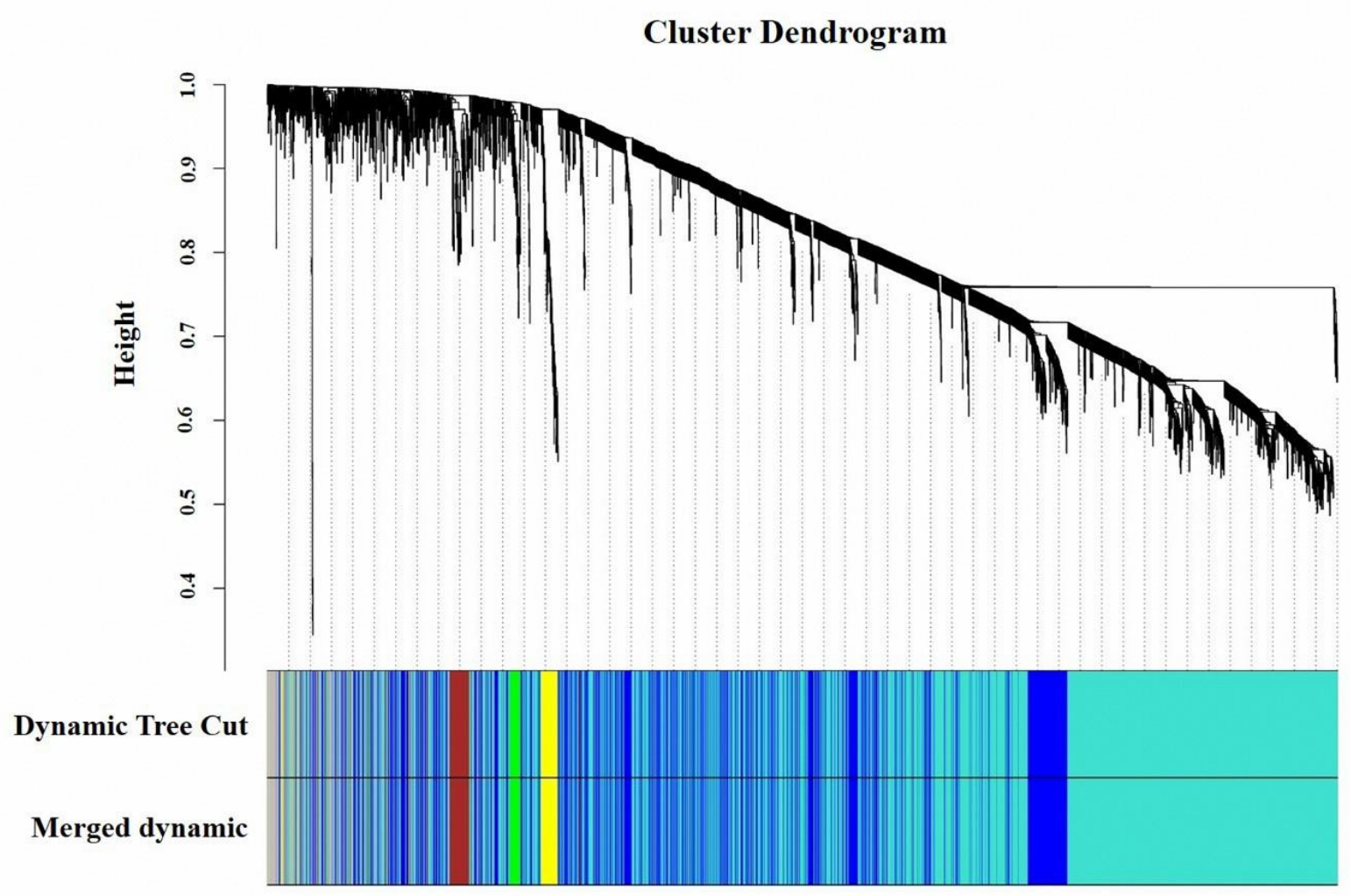

Fig.S4. Cluster dendrogram and module assignment from WGCNA. The branches correspond to highly interconnected groups of genes. Colors in the horizontal bar represent the modules. 

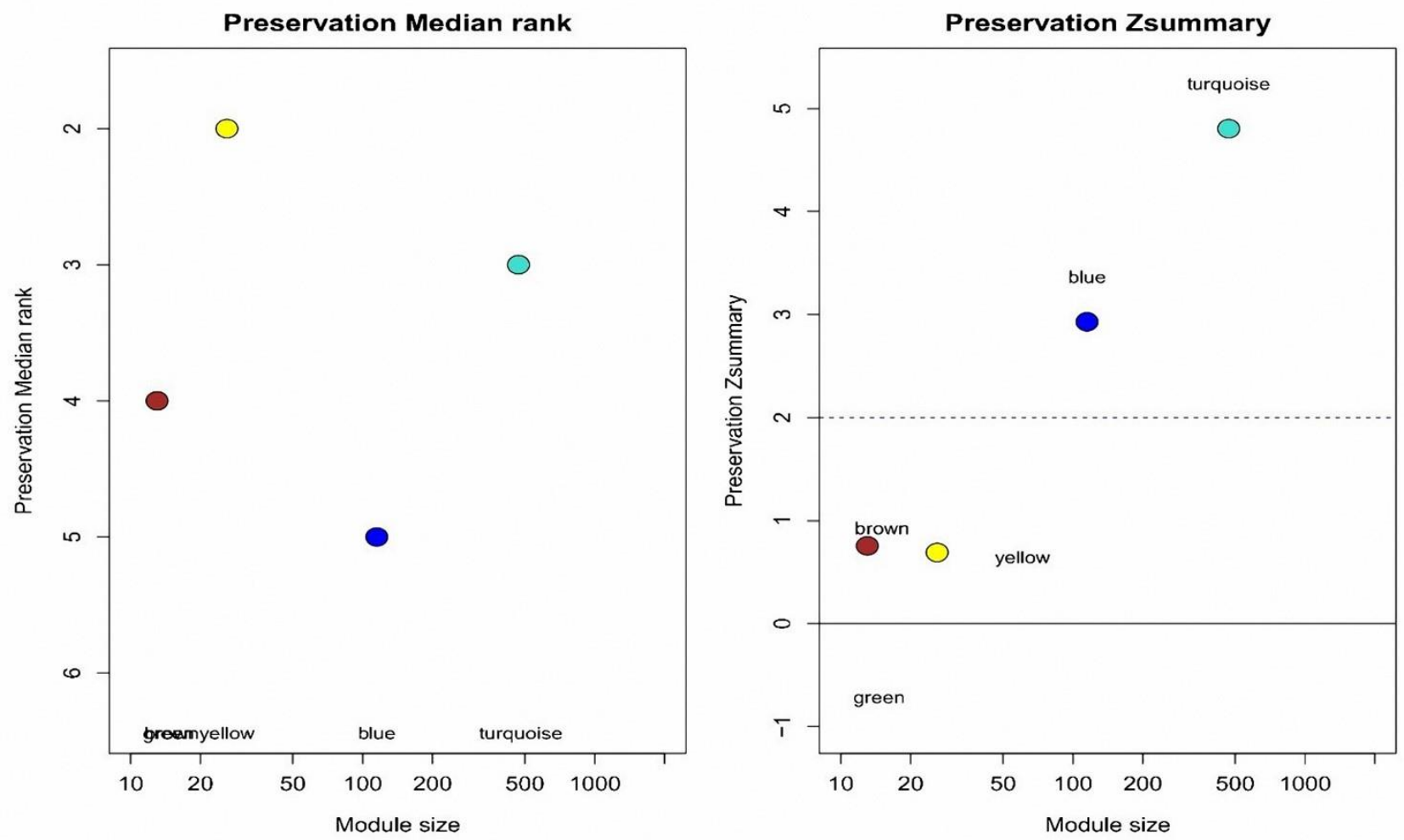

Fig.S5. Preservation of GSE35776 modules in comparison with GSE26125 dataset. Each module is represented by its color-code and name. Left figure indicate the preservation median rank. This factor is independent from module size and high median ranks correspond to low preservation. Right figure indicates Zsummary score. The dashed blue and black lines show the thresholds $Z_{\text {summary }}=0$ and $Z_{\text {summary }}=2$.

Module Membership vs. gene significance

cor $=0.94, \mathrm{p}<1 \mathrm{e}-200$

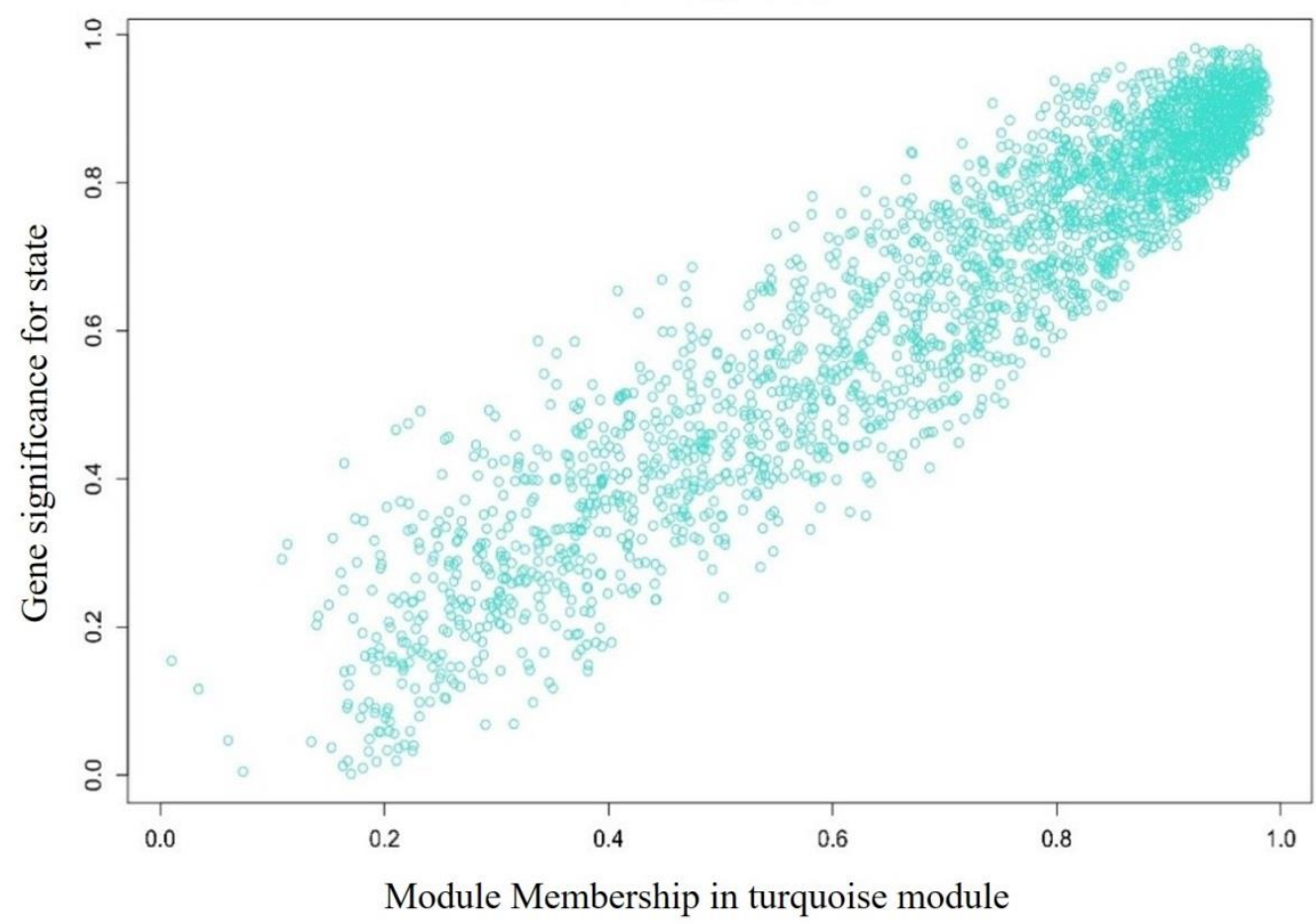

Fig.S6. Module features of GS and MM. Modules significantly correlated with TOF status (TOF vs Control). Each point represents an individual gene within each module, which are plotted by GS on the $y$-axis and MM on the $\mathrm{x}$-axis. 
network, a molecular mechanism for TOF pathogenicity is suggested in Figure 5.

\section{Discussion}

Tetralogy of Fallot is the most common congenital heart disease, which is largely unknown for the exact pathogenesis mechanism. Hence, the complications of TOF remain a lifetime disease and does not cure by surgical repair (Gu et al., 2014). A better understanding of TOF etiology would be necessary not only for family counseling and prenatal diagnosis, but also to identify new treatment and preventive approaches such as dietary supplementation for identified high-risk pregnancies (Erdal et al., 2007). Moreover, despite advanced surgical approaches for the patient with TOF, tremendous outstanding issues have remained to be addressed in order to ensure the highest efficiency of future treatments and quality of life (van der Ven et al., 2019).

To this end, our study was performed to clarify molecular pathogenesis associated with TOF using WGCNA. In the present study, we analyzed the GSE35776 dataset including 16 TOF samples and 8 normal samples. Co-expression network analysis by WGCNA suggested that a highly preserved turquoise module with 2493 genes was significantly correlated to TOF. The turquoise module encompassed 5 Hubgenes with GS and MM $>0.95$ and LogFC $>2.00$ including PSMA2, MYL12A, chromosome 11 open reading frame 71 (C11ORF71), COMMD6 and CREG1, which exhibited the most significant association with TOF trait.

Further, gene ontology (GO) functional and KEGG pathway enrichment analyses using ClueGo revealed that the turquoise module was enriched into the 18 main biological process categories $(P<0.05)$ which directly related to TOF. For instance, the roles exerted by migration and differentiation of neural crest on secondary heart field (SHF) development are largely delineatedv (Restivo et al., 2006). The ablation of the cardiac or cranial neural crest results in a spectrum conotruncal defects such as TOF (Kirby and Waldo, 1990; Yamagishi, 2020). Therefore, TOF has already been considered to be a conotruncal heart defect caused by implications in neural crest cell migration and differentiation (Di Felice and Zummo, 2009). However, most of these specific enriched pathways have not still reported by literature and imperfect picture of TOF related mechanisms have been elucidated; this deserves further mechanistic investigations are required in this area.

Despite improvements in minimizing postoperative morbidity of surgical repair, CPB has been demonstrated to induce inappropriate molecular reprogramming of cardiac myocytes led to increased oxidative stress, inflammatory response, chemokine over-production, myocardial damage and eventually compensatory mechanisms which is presumed to be regulated by genetic factors (Manrique et al., 2020; Raggi et al., 2020; Rosenthal et al., 2020). However, transcriptional changes of the interested Hub genes indicate beneficial role of $\mathrm{CPB}$, albeit slightly, in ameliorating gene expression alternations in the ToF myocardium. Consistent with this results, a recent microarray study revealed that CPB could induce higher levels of several genes with cardioprotective functions such as genes that exert anti-inflammatory and antioxidant effects againist CPB-induced ischemia/reperfusion (I/R) myocardial injury (Raggi et al., 2020). Furthermore, in consistent with previous reports, transcriptomic changes of selected Hub genes in response to life-long chronic hypoxia in ToF patients revealed elevated expression levels of Hub genes that are mainly involved in proliferation, growth/morphogenesis, remodeling pathways (Ghorbel et al., 2010; Raggi et al., 2020; Zhao et al., 2019).

The candidate gene, PSMA2, is a component of $20 \mathrm{~S}$ core proteasome complex which is associated with two 19S regulatory particles to form $26 \mathrm{~S}$ proteasome involved in the ubiquitin-proteasome system (UPS), the main protein degradation system in the heart (Nandi et al., 2006). The possible mechanism of PSMA2 involvement in TOF progression can be explained in at least four main cellular pathways discussed below. However, there may be other alternative mechanisms, which have not been considered.

Canonical Wnt/ $\beta$-catenin pathway: There is an emerging consensus suggesting that the observed malformations in TOF may be caused by altered proliferation, migration or differentiation of cardiac progenitor cells from the SHF which migrates to the primary heart tube during heart development (Di Felice and Zummo, 2009). Accordingly, Wnt signaling with either canonical or non-canonical pathways has 
been implicated in mesoderm formation, specification and proliferation, cell adhesion and cell polarity (Karami et al., 2013). Wnt signaling activity is controlled in a spatial-temporal manner during heart development (Liu et al., 2014; Swinarski, 2017). Wnt signaling is triggered by the interaction of transmembrane frizzled and Wnt ligands that activates downstream $\beta$-catenin and small Rho and Rac family GTPases via the disheveled protein (Henderson et al., 2006). In turn, $\beta$-catenin enters the nucleus leading to regulating the second heart SHF proliferation program (Rochais et al., 2009). The disruption of this pathway was associated with severe outflow tract (OFT) malformations that could involve a spectrum of conotruncal defects in mouse models, including pulmonary stenosis and double outlet RV (Di Felice and Zummo, 2009; Touma et al., 2017). Moreover, recent evidence has revealed that lower expression of Wnt11 associates with lower O2 saturation in the TOF infants, suggesting that Wnt11 signaling appears to be important in the RV-specific impact of hypoxia in postnatal heart of newborns with cyanotic CHDs (Touma et al., 2017). It is well known that in the absence of the Wnt, $\beta$-catenin phosphorylated and ubiquitinated results in proteasomal degradation (Yi et al., 2017). Therefore, the up-regulation of PSMA2 in TOF disease as a component of UPS may subsequently lead to overdegeneration/degradation of $\beta$-catenin, which is responsible for subsequent outcomes in TOF patients.

Regulation of hypoxia-inducible factor (HIF)-1a: The HIF-1 $\alpha$ is an important transcription factor that intersects with numerous signaling pathways. HIF-1a expression and stabilization are required for normal cardiovascular system development. Moreover, HIF$1 \alpha$ as the most important transcriptional factor associated with cyanotic TOF plays a putative regulatory role in oxygen sensing, homeostasis and cardiac adaptation to moderate chronic hypoxemia (Zhao et al., 2019). However, HIF-1a protein is rapidly degraded under normoxia condition. Experimental studies have demonstrated that the proteasomal inhibitors, bortezomib, inhibits tumor adaptation to hypoxia by functionally inhibiting HIFa-1 (Befani et al., 2012). This phenomenon provides the basis for the counterintuitive theory entitled activation by destruction. Despite HIF-1 $\alpha$ being a well-known proteasome target, sustained transcription mediated by HIF-1 $\alpha$ requires proteasomal activity to remove "spent" activators and to reset the promoter (Kaluz et al., 2006). Over-activation of the HIF-1a by cited 2 mutations, causes serious cardiovascular abnormalities during prenatal development, including pulmonary arterial stenosis and ventricular septal defects accompanied by conotruncal defects, that are known as the main features of TOF (Yin et al., 2002). In the present study, the up-regulation of PSMA2 in TOF patients would, therefore, be the main culprit of HIF-1 $\alpha$ over-activation that plays a key role during TOF development

RET signaling: The RET proto-oncogene is a receptor tyrosine kinase involved in numerous cellular mechanisms, including cell proliferation, cell migration and cell differentiation (O'Leary et al., 2016). The RET gene has been associated with the development of TOF and the abnormality of cardiovascular system morphology such as conotruncal defects and ventricular conduction impairments. Moreover, RET can also activate Rho family GTPases, including Rho, Rac and Cdc42, which are involved in the actin cytoskeleton remodeling responsible for cell morphology, polarity and migration. Unlike other RTKs that are trafficked to lysosomes for degradation, RET was shown to be rapidly ubiquitinated and degraded by the proteasome (Fukuda et al., 2002). It is suggested that the up-regulation of PSMA2, involving in UPS degeneration would contribute to RET signaling impairment.

P53 signaling: Studies suggest that bortezomib treatment as a proteasomal inhibitor, can significantly suppress the elevation of right ventricular hypertrophy and pulmonary vascular remodeling in hypoxiaexposed mice (Kim et al., 2012). Additionally, the inhibitory effects of bortezomib on prostate cancer cells and vascular smooth muscle cells proliferation have been well established. With respect to these findings, UPS plays a key role in cell cycle regulation by accurately degrading the cell cycle-inhibitor proteins, including p53 and p21 (Kim et al., 2012). In line with this, emerging evidence support a driving role of p53 in the regulation of hypoxia-induced gene expression alternations of TOF myocardium (Zhao et al., 2019). Therefore, it can potentially support our 
findings, in which up-regulation of PSMA2 can play an important role in fibrosis and cellular hypertrophy in TOF patients with right ventricular outflow tract obstruction.

Moreover, cellular repressor of E1A stimulated genes 1 (CREG1) is a secreted protein located in the lysosome, which is required for mouse embryonic stem cells differentiation to cardiomyocytes (Liu et al., 2016) and to regulate cardiac hypertrophy and fibrosis in heart failure (Shahneh et al., 2013; Wang et al., 2017). Although CREG1 contributes to the transcriptional control of cell growth (Di Bacco and Gill, 2003), the negative/positive regulation of CREG1 remains controversially in the current literature and a paradoxical role has been observed through various pathways (Clark et al., 2016). Our results suggest that the up-regulation of CREG1 in TOF patients may have a positive role in right ventricular hypertrophy, mediated by retinoblastoma protein $1(R b 1)$ inhibition. The $R b 1$ is a negative cell cycle regulator, which acts by binding to the E2F1 transcription factor induced by hypoxia and results in right ventricular hypertrophy in cyanotic TOF infants (Abe et al., 2016; Touma et al., 2017).

Furthermore, MYL12A is a myosin regulatory subunit that is involved in regulating cytoskeleton remodeling by Rho GTPases via the non-canonical Wnt Signaling. Also, Myl12A has been implicated in the establishment of the planar cell polarity during later stages of cardiac OFT development, especially in myocardial differentiation of the OFT cushion during septum formation and cardiac muscle contraction. Perturbations of this gene and associated processes are important contributors to TOF anomalies (O'Leary et al., 2016; Olson and Nordheim, 2010; Rochais et al., 2009).

Although the findings of this in silico study may shed light on the understanding of TOF pathogenicity, we have not verified the biological functions of the selected hub genes in TOF, nor have we determined how suggested miRNAs and approved drugs targets the hub genes related to TOF. Therefore, more in vitro and in vivo experiments for blood and tissue verification of these hub-genes and relative pathways are still needed.

\section{Conclusion}

Identification of the gene targets specific to the development of $\mathrm{CHD}$ will help to a better understanding of how this disease develops, to provide appropriate counseling for families and to invent new tools for early diagnosis and intervention. In this study, we identified a novel module involved in TOF pathogenesis and discovered putative diagnostic biomarkers, including PSMA2, MYL12A, C11ORF71, COMMD6 and CREG1 which can provide promising diagnostics and therapeutic targets for TOF. Thus, our results provide new and more indepth insights for further investigations to reveal the mechanisms by which these genes play their roles in TOF. Although the literature annotation and imperfect picture of TOF-related mechanisms have not yet been reported on these specific enriched pathways. Fundamental study on these new targets should be performed to establish their diagnostic and or therapeutic values for clinical intervention.

\section{Acknowledgments}

This research was supported by Tabriz University of Medical Sciences and Birjand University of Medical Sciences. The authors want to acknowledge them for their support.

\section{Conflict of interest}

The authors declare there are no conflicts of interest.

\section{References}

Abe K, Shinoda M, Tanaka M, Kuwabara Y, Yoshida K, Hirooka Y, McMurtry IF, Oka M, Sunagawa K. Haemodynamic unloading reverses occlusive vascular lesions in severe pulmonary hypertension. Cardiovasc Res 2016; 111: 16-25. https://doi.org/10.1093/cvr/ crw070

Apitz C, Webb GD, Redington AN. Tetralogy of fallot. Lancet 2009 374: 1462-71. https://doi.org/10.1016/ S0140-6736(09)60657-7

Bartlett H, Veenstra GJ, Weeks DL. Examining the cardiac NK-2 genes in early heart development. Pediatr Cardiol 2010; 3: 335-41. https://doi.org/10.1007/s00246-0099605-0

Befani CD, Vlachostergios PJ, Hatzidaki E, Patrikidou A, Bonanou S, Simos G, et al. Bortezomib represses HIF$1 \alpha$ protein expression and nuclear accumulation by inhibiting both PI3K/Akt/TOR and MAPK pathways in prostate cancer cells. J Mol Med 2012; 90: 45-54. https://doi.org/10.1007/s00109-011-0805-8

Bindea G, Mlecnik B, Hackl $H$, Charoentong P, Tosolini M, Kirilovsky A, et al. ClueGO: a Cytoscape plug-in to decipher functionally grouped gene ontology and pathway annotation networks. Bioinformatics 2009; 25: 
1091-3. https://doi.org/10.1093/bioinformatics/btp101

Bittel DC, Kibiryeva N, Marshall JA, O'Brien JE. MicroRNA421 dysregulation is associated with tetralogy of Fallot. Cells 2014; 3: 713-23. https://doi.org/10.3390/cells303 0713

Cecchetto A, Rampazzo A, Angelini A, Bianco LD, Padalino M, Stellin G, et al. 2010. From molecular mechanisms of cardiac development to genetic substrate of congenital heart diseases Future Cardiol 2010; 6: 37393. https://doi.org/10.2217/fca.10.10

Clark DJ, Mei Y, Sun S, Zhang H, Yang AJ, Mao L. Glycoproteomic approach identifies KRAS as a positive regulator of CREG1 in non-small cell lung cancer cells. Theranostics 2016; 6: 65-77. https://doi.org/10.7150/ thno.12350

d'Udekem Y, Ovaert C, Grandjean F, Gerin V, Cailteux M, Shango-Lody P, et al. Tetralogy of Fallot: transannular and right ventricular patching equally affect late functional status. Circulation 2000; 102: lii-116. https://doi.org/10.1161/01.CIR.102.suppl_3.III-116

Di Bacco A, Gill G. The secreted glycoprotein CREG inhibits cell growth dependent on the mannose-6phosphate/insulin-like growth factor II receptor. Oncogene 2003; 22: 5436-45. https://doi.org/10.1038/ sj.onc. 1206670

Di Felice V, Zummo G. Tetralogy of fallot as a model to study cardiac progenitor cell migration and differentiation during heart development. Trends Cardiovasc Med 2009; 19: 130-5. https://doi.org/ 10.1016/j.tcm.2009.07.004

Erdal E, Erdal C, Bulut G, Kunter I, Kir M, Atabey N, Açikel Ü. Mutation analysis of the Vangl2 coding region revealed no common cause for tetralogy of fallot. $\mathrm{J}$ Int Med Res 2007; 35: 867-72. https://doi.org/10.1177/ 147323000703500614

Fukuda T, Kiuchi K, Takahashi M. Novel mechanism of regulation of Rac activity and lamellipodia formation by RET tyrosine kinase. J Biol Chem 2002; 277: 19114-21. https://doi.org/10.1074/jbc.M200643200

Gautier L, Cope L, Bolstad BM, Irizarry RA. Affy-analysis of Affymetrix GeneChip data at the probe level. Bioinformatics 2004; 20: 307-15. https://doi.org/10. 1093/bioinformatics/btg405

Gentleman RC, Carey VJ, Bates DM, Bolstad B, Dettling M, Dudoit $S$, et al. Bioconductor: open software development for computational biology and bioinformatics. Genome Biol 2004; 5: R80. https://doi.org/10.1186/gb-2004-5-10-r80

Ghorbel MT, Cherif M, Jenkins E, Mokhtari A, Kenny D, Angelini GD, et al. Transcriptomic analysis of patients with tetralogy of Fallot reveals the effect of chronic hypoxia on myocardial gene expression. J Thorac Cardiovasc Surg 2010; 140: 337-45. https://doi.org/10.1016/j.jtcvs.2009.12.055

Gu Q, Chen XT, Xiao YB, Chen L, Wang XF, Fang J, et al. Identification of differently expressed genes and small molecule drugs for tetralogy of Fallot by bioinformatics strategy. Pediatr Cardiol 2014; 35: 863-9. https://doi.org/10.1007/s00246-014-0868-8
Henderson DJ, Phillips HM, Chaudhry B. Vang-like 2 and noncanonical Wnt signaling in outflow tract development. Trends Cardiovasc Med 2006; 16: 38-45. https://doi.org/10.1016/j.tcm.2005.11.005

Hu DL, Chen FK, Liu YQ, Sheng YH, Yang R, Kong XQ, et al. GATA-4 promotes the differentiation of P19 cells into cardiac myocytes. Int J Mol Med 2010; 26: 365-72.

Kaluz S, Kaluzová M, Stanbridge EJ. Proteasomal inhibition attenuates transcriptional activity of hypoxia-inducible factor 1 (HIF-1) via specific effect on the HIF-1a Cterminal activation domain. Mol Cell Biol 2006; 26: 5895-907. https://doi.org/10.1128/MCB.00552-06

Karami H, Baradaran B, Esfahani A, Estiar MA, NaghaviBehzad M, Sakhinia M, et al. siRNA-mediated silencing of survivin inhibits proliferation and enhances etoposide chemosensitivity in acute myeloid leukemia cells. Asian Pacific J Cancer Prev 2013; 14: 7719-24. https://doi.org/10.7314/APJCP.2013.14.12.7719

Kim SY, Lee JH, Huh JW, Kim HJ, Park MK, Ro JY, et al. Bortezomib alleviates experimental pulmonary arterial hypertension. Am J Respir Cell Mol Biol 2012; 47: 698708. https://doi.org/10.1165/rcmb.2011-0331OC

Kirby ML, Waldo KL. Role of neural crest in congenital heart disease. Circulation 1990; 82: 332-40. https://doi.org/10.1161/01.CIR.82.2.332

Langfelder P, Horvath S. WGCNA: an R package for weighted correlation network analysis. BMC Bioinform 2008; 9: 559. https://doi.org/10.1186/1471-2105-9-559

Liang D, Xu X, Deng F, Feng J, Zhang H, Liu Y, et al. MiRNA-940 reduction contributes to human Tetralogy of Fallot development. J Cell Mol Med 2014; 18: 1830-9. https://doi.org/10.1111/jcmm.12309

Liu J, Fukunaga-Kalabis M, Li L, Herlyn M. Developmental pathways activated in melanocytes and melanoma. Arch Biochem Biophys 2014; 563: 13-21. https://doi.org/10.1016/j.abb.2014.07.023

Liu J, Qi Y, Li S, Hsu SC, Saadat S, Hsu J, et al. CREG1 interacts with Sec8 to promote cardiomyogenic differentiation and cell-cell adhesion. Stem Cells 2016; 34: 2648-60. https://doi.org/10.1002/stem.2434

Manrique AM, Vargas DP, Palmer D, Kelly K, Litchenstein SE. The effects of cardiopulmonary bypass following pediatric cardiac surgery. In: Munoz R, Morell V, da Cruz E, Vetterly C, da Silva J. (eds) Critical Care of Children with Heart Disease. Springer, Cham, 2020, pp. 113-129. https://doi.org/10.1007/978-3-030-21870-6_10

Meijer JM, Pieper PG, Drenthen W, Voors AA, RoosHesselink JW, van Dijk AP, et al. Pregnancy, fertility, and recurrence risk in corrected tetralogy of Fallot. Heart 2005; 91: 801-5. https://doi.org/10.1136/hrt.2004. 034108

Michielon G, Marino B, Formigari R, Gargiulo G, Picchio F, Digilio MC, et al. Genetic syndromes and outcome after surgical correction of tetralogy of fallot. Ann Thorac Surg 2006; 81: 968-75. https://doi.org/10.1016/ j.athoracsur.2005.09.033

Nandi D, Tahiliani P, Kumar A, Chandu D. The ubiquitinproteasome system. J Biosci 2006; 31: 137-55. https://doi.org/10.1007/BF02705243 
Nemer G, Fadlalah F, Usta J, Nemer M, Dbaibo G, Obeid $M$, et al. A novel mutation in the GATA4 gene in patients with Tetralogy of Fallot. Hum Mutat 2006; 27 : 293-4. https://doi.org/10.1002/humu.9410

Nollert G, Fischlein T, Bouterwek S, Böhmer C, Klinner W, Reichart B. Long-term survival in patients with repair of tetralogy of Fallot: 36-year follow-up of 490 survivors of the first year after surgical repair. J Am Coll Cardiol 1997; 30: 1374-83. https://doi.org/10.1016/S07351097(97)00318-5

O'Leary NA, Wright MW, Brister JR, Ciufo S, Haddad D, McVeigh $R$, et al. Reference sequence (RefSeq) database at NCBI: Current status, taxonomic expansion, and functional annotation. Nucleic Acids Res 2016; 44: D733-45. https://doi.org/10.1093/nar/ gkv1189

Olson EN, Nordheim A. Linking actin dynamics and gene transcription to drive cellular motile functions. Nat Rev Mol Cell Biol 2010; 11: 353-65. https://doi.org/ 10.1038/nrm2890

Pei G, Chen L, Zhang W. WGCNA application to proteomic and metabolomic data analysis. Methods Enzymol 2017; 585: 135-158. https://doi.org/10.1016/bs.mie. 2016.09.016

Raggi F, Cangelosi D, Becherini P, Blengio F, Morini M, Acquaviva $M$, et al. Transcriptome analysis defines myocardium gene signatures in children with ToF and ASD and reveals disease-specific molecular reprogramming in response to surgery with cardiopulmonary bypass. J Transl Med 2020; 18: 1-20. https://doi.org/10.1186/s12967-020-02210-5

Restivo A, Piacentini G, Placidi S, Saffirio C, Marino B. Cardiac outflow tract: a review of some embryogenetic aspects of the conotruncal region of the heart. Anat Rec Part A Discov Mol Cell Evol Biol 2006; 288: 936-43. https://doi.org/10.1002/ar.a.20367

Rochais F, Mesbah K, Kelly RG. Signaling pathways controlling second heart field development. Circ Res 2009; 104: 933-42. https://doi.org/10.1161/ CIRCRESAHA.109.194464

Rosenthal LM, Tong G, Wowro S, Walker C, Pfitzer C, Böttcher W, et al. A prospective clinical trial measuring the effects of cardiopulmonary bypass under mild hypothermia on the inflammatory response and regulation of cold-shock protein RNA-binding Motif 3 . Ther Hypothermia Temp Manag 2020; 10: 60-70. https://doi.org/10.1089/ther.2018.0038

Shahneh FZ, Valiyari S, Azadmehr A, Hajiaghaee R, Yaripour S, et al. Inhibition of growth and induction of apoptosis in fibrosarcoma cell lines by echinophora platyloba DC: in vitro analysis. Adv Pharmacol Sci 2013; 2013: 1-7. https://doi.org/10.1155/2013/ 512931

Shannon P, Markiel A, Ozier O, Baliga NS, Wang JT, et al.
Cytoscape: a software environment for integrated models of biomolecular interaction networks. Genome Res 2003; 13: 2498-504. https://doi.org/10.1101/ gr.1239303

Swinarski M. PCP-driven cardiac remodeling couples changes in actomyosin tension with myocyte differentiation. 2017.

Touma M, Kang X, Gao F, Zhao Y, Cass AA, Biniwale R, et al. Wnt11 regulates cardiac chamber development and disease during perinatal maturation. JCl insight 2017; 2: 1-18. https://doi.org/10.1172/jci.insight.94904

van der Ven JPG, van den Bosch E, Bogers AJCC, Helbing WA. Current outcomes and treatment of tetralogy of Fallot. F1000Res 2019; 8: F1000 Faculty Rev-1530. https://doi.org/10.12688/f1000research.17174.1

Villafañe J, Feinstein JA, Jenkins KJ, Vincent RN, Walsh EP, Dubin AM, et al. Hot topics in tetralogy of fallot. $J$ Am Coll Cardiol 2013; 62: 2155-66. https://doi.org/10.1016/j.jacc.2013.07.100

Wang B, Shi G, Zhu Z, Chen H, Fu Q. Sexual difference of small RNA expression in Tetralogy of Fallot. Sci Rep 2018; 8: 1-8. https://doi.org/10.1038/s41598-018-312436

Wang F, Jia J, Rodrigues B. Autophagy, metabolic disease, and pathogenesis of heart dysfunction. Can $\mathrm{J}$ Cardiol 2017; 33: 850-9. https://doi.org/10.1016/j.cjca. 2017.01.002

Wang XM, Zhang K, Li Y, Shi K, Liu YL, Yang YF, et al. Screening miRNA and their target genes related to tetralogy of Fallot with microarray. Cardiol Young 2014; 24: 442-6. https://doi.org/10.1017/S104795111300053X

Xu J, Lin Y, Si L, Jin G, Dai J, Wang C, et al. Genetic variants at $10 p 11$ confer risk of tetralogy of fallot in Chinese of Nanjing. PLoS One 2014: 9: 3-7. https://doi.org/10.1371/journal.pone.0089636

Yamagishi H. Cardiac neural crest. Cold Spring Harb Perspect Biol 2020; 18: a036715. https://doi.org/ 10.1101/cshperspect.a036715

Yi JJ, Paranjape SR, Walker MP, Choudhury R, Wolter JM, Fragola G, et al. The autism-linked UBE3A T485A mutant E3 ubiquitin ligase activates the $\mathrm{Wnt} / \beta$-catenin pathway by inhibiting the proteasome. J Biol Chem 2017; 292: 12503-15. https://doi.org/10.1074/jbc.M117. 788448

Yin Z, Haynie J, Yang X, Han B, Kiatchoosakun S, Restivo $J$, et al. The essential role of Cited2, a negative regulator for HIF-1 $\alpha$, in heart development and neurulation. Proc Natl Acad Sci USA 2002; 99: 1048893. https://doi.org/10.1073/pnas.162371799

Zhao Y, Kang X, Gao F, Guzman A, Lau RP, Biniwale R, et al. Gene-environment regulatory circuits of right ventricular pathology in tetralogy of fallot. $\mathrm{J}$ Mol Med 2019; 97: 1711-22. https://doi.org/10.1007/s00109019-01857-y 